\title{
PLANETARY CYCLOID ROLLER GEAR REDUCER
}

\author{
Nguyen Thien Phuc \\ Hanoi University of Technology
}

\begin{abstract}
In this paper we present some results of the shaping tooth profile and the method of the relationships between gear parameters and of the analysis for properties of the planetary cycloid roller gear reducer.
\end{abstract}

\section{Introduction}

A tendency to replace sliding friction by rolling friction has contributed to the development of machinery. The ball spline and ball screw are the innovative linear motion system. However, the introduction of rolling contact to rotational motion by gear was never achieved. A planetary cycloid gear reducer, utilizing rolling contact for gear is presented following.

A sectional drawing of the planetary cycloid roller gear reducer is shown in Fig. 1.

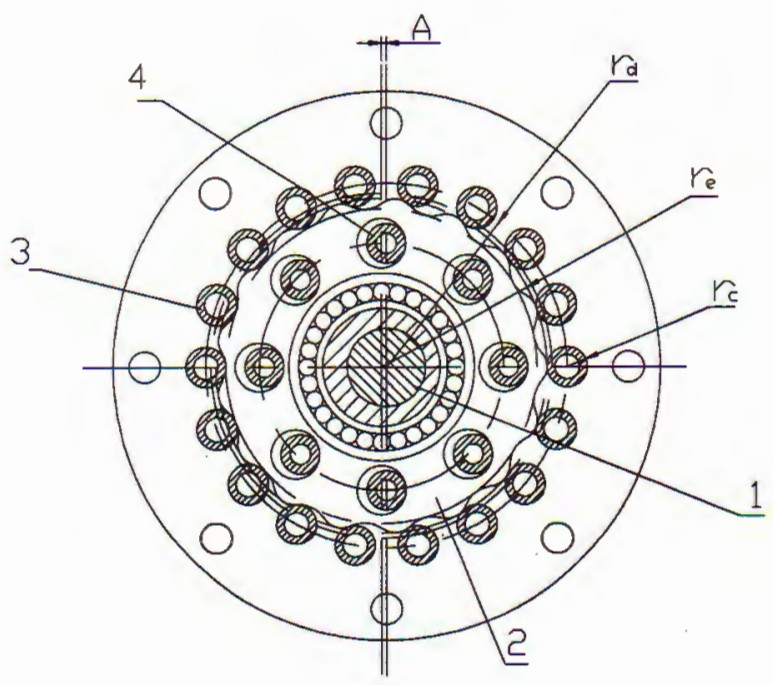

Fig. 1 
There are four basic components: 1-the input shaft with eccentric and bearing; 2-cycloid disks; 3 -a ring gear housing with rollers; 4-an output shaft with drive rollers.

The planetary cycloid pin gear reducer was first developed by Sanhikov [1] in the year 1948. Today, there are very few manufacturers producing the planetary cycloid pin gear reducer with some changes. CENTA Transmission Ltd (USA) and HAPDONG Machinery Co. (Korea) are among the mentioned above manufacturers. However, we know only their marketing informations from Internet.

The following are our reseaches on the method of formation gear profile and its manufacturing, on the establishment of the relationships between gear parameters and on the analysis for properties of the planetary cycloid roller gear reducer.

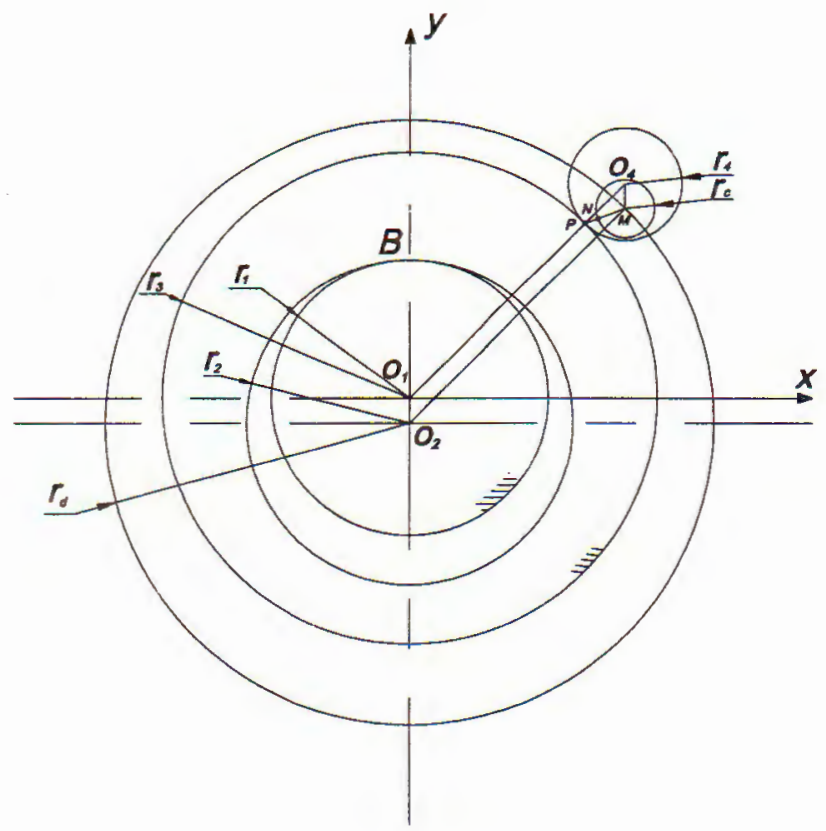

Fig. 2

\section{Operating principle}

The basic concept and principle of operation are as follows. The cycloid disk is mounted on the eccentric bearing which rotates at the speed of the input shaft causing the cycloid disk to roll around the inside of the ring gear housing. As there is one less cycloid tooth on the disk than the number of rollers in the ring gear housing, the cycloid disk rotates in the opposite direction to the input shaft by one tooth pitch for each revolution of the input eccentric. Thus output rotation is created in the opposite direction to input rotation and at a reduced speed. The reduction 
ratio is determined by the number of teeth on the cycloid disk, e.g. 35 teeth on the cycloid disk and 36 rollers in the ring gear housing gives a reduction of $35: 1$. The rotation of the cycloid disk is transmitted to the output shaft by a number of rollers projecting through holes in the disk.

In order to improve the loading capacity and to dispose of the backlash we can use a two-disk system. This serves to double the number of points on the periphery transmitting torque at any time and by displaying the disks through $180^{\circ}$ provides balanced centrifugal forces and a smooth operation. The resulting reduced output speed is coaxial with the input and is claimed to be free vibration.

In order to expand the range of reduction ratio we can use two or three stage units. Thus there are single, double and triple reductions.

\section{Property analysis}

3.1. The planetary cycloid roller gear reducers have a wide range of reduction ratios. Based on a diagram of velocity vectors, the velocity ratio is given by [1]:

$$
i=\frac{1}{1-\frac{Z_{2}}{Z_{1}}}=\frac{Z_{1}}{Z_{1}-Z_{2}} .
$$

Because of the roller numbers of ring gear housing $\left(Z_{2}\right)$ are one more than the teeth numbers of cycloid disk $\left(Z_{1}\right)$, so that $i=-Z_{1}$. We can use the single stage reduction or multi-stage reduction. Single stage reduction ratios from $6: 1$ to $87: 1$ and multi-stage reduction ratios in excess of some millions are possible.

3.2. The operating efficiency $\eta$ of the planetary cycloid roller gear reducer is determined by [1]:

$$
\eta=\frac{\frac{Z_{2}}{Z_{1}}-1}{\frac{Z_{2}}{Z_{1} \cdot \eta_{12}}-1}
$$

where, $\eta_{12}$ is the efficiency of the gear transmission. Due to the attendance of the rollers the sliding friction usually present is replaced by rolling friction. Because of this lowered friction, these reducers have efficiencies of $90 \%$ or higher.

3.3. These drivers offer compact size, silent operation and heavy loads. These advantages are explained by following. The existence of the convexo-concave contact with a continuous oil-lubricating film of the conjugate gear profiles, plays the decisive role in attaining the goals [3].

Due to their contruction the number of teeth under engagement is very high. So that the load is distributed over many teeth at any moment and these reducers can carry higher loads, and they are quieter and smoother running. 
3.4. One factor that is considered in gear design for the modern mechanical power transmissions and was mentioned previously, is backlask. This is the shortest distance between noncontacting surfaces of adjacent teeth and is evidenced by nonmovement of the gears for a proportional amount of time when the direction of rotation is changed by the motor. The amount of nonmovement is directly related to amount of backlash. As it was mentioned previously, in this reducer the backlash may be disposed of by using the two-disk system.

\section{Formation of the gear profile and method of manufacturing}

It is known, an epitrochoid curve belongs to a family of cycloidal curves and this curve may be created by two ways [2]. In the first way this curve is a trajectory of a point $M$, closely connected to circle with a radius $r_{2}$, while this circle is rolling upon a circle with radius $r_{1}$ without slipping. In the second way this curve is a trajectory of a point $M$, closely connected to circle with a radius $r_{4}$, while this circle is rolling upon a circle with radius $r_{3}$ without slipping, as shown in Fig. 2 . The relationships between these radii are given by [2]:

$$
\begin{aligned}
& r_{1}=\overline{O_{4} M} \cdot \frac{r_{3}}{r_{4}}=a \cdot \frac{r_{3}}{r_{4}} \\
& r_{2}=a \cdot \frac{r_{3}+r_{4}}{r_{4}} .
\end{aligned}
$$

In fact, the roller is present in the place of the point $M$. Therefore, the gear profile is not a trajectory of the point $M$, but is a curve, which stands at a normal distance of the roller's radius $r_{c}$ from the point $M$. This curve can be obtained by drawing method [2]. Here, we briefly present some of the attending mathematical description of this curve.

In accordance with the law of conjugate gear tooth action, the normals to the profiles of these teeth at all points of contact must pass through a pitch point $P$, that is point of contact of two pitch circles with radii $r_{3}$ and $r_{4}$, as shown in Fig. 3 .

Because of the outer circle of roller is one of the conjugate profiles, its normal must pass through the pitch point $\mathrm{P}$ and the center $M$ of this cicrle with radius $r_{c}$. Therefore, the point of contact $N$ is determined by a point of intersection between the line $M P$ and the circle with radius $r_{c}$. On the condition that three points $M$, $P$ and $N$ must be stay in a straight line, we may write:

$$
\frac{y_{M}-y_{N}}{y_{M}-y_{P}}=\frac{x_{M}-x_{N}}{x_{M}-x_{P}}
$$

and on the condition that the point $M$ belongs to the circle with radius $r_{c}$, we have:

$$
\left(x_{M}-x_{N}\right)^{2}+\left(y_{M}-y_{N}\right)^{2}=r_{c}^{2}
$$


"Based on this equations (4.3) and (4.4), we have

$$
\begin{aligned}
& x_{N}=x_{M}-\left(x_{M}-x_{P}\right) \frac{y_{M}-y_{N}}{y_{M}-y_{P}} \\
& y_{N}=y_{M}-\frac{r_{c}\left(y_{M}-y_{P}\right)}{\sqrt{\left(x_{M}-x_{P}\right)^{2}+\left(y_{M}-y_{P}\right)^{2}}} .
\end{aligned}
$$

The coordinates of the point $P$ are given by (see Fig. 3)

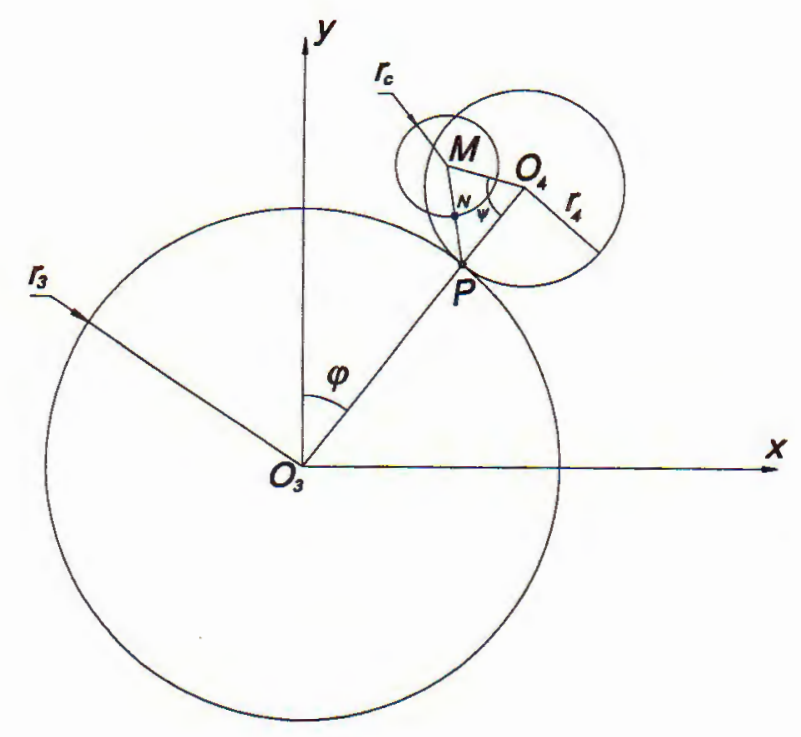

Fig. 3

$$
\begin{aligned}
& x_{p}=r_{3} \sin \varphi, \\
& y_{p}=r_{3} \cos \varphi .
\end{aligned}
$$

As shown in Fig. 3 the position of the point $M$ is determined by

$$
\overline{O_{3} M}=\overline{O_{3} O_{4}}+\overline{O_{4} M}
$$

From here, we have

$$
\begin{aligned}
& x_{M}=\left(r_{3}+r_{4}\right) \sin \varphi-a \sin (\varphi+\psi), \\
& y_{M}=\left(r_{3}+r_{4}\right) \cos \varphi-a \cos (\varphi+\psi)
\end{aligned}
$$


Because of the two circles with radii $r_{3}$ and $r_{4}$ were rolling upon each other without slipping, so that

$$
\psi=\frac{r_{3}}{r_{4}} \varphi,
$$

and the equations (4.9) may be written in the form:

$$
\begin{aligned}
& x_{M}=\left(r_{3}+r_{4}\right) \sin \varphi-a \sin \left[\varphi\left(1+\frac{r_{3}}{r_{4}}\right)\right], \\
& y_{M}=\left(r_{3}+r_{4}\right) \cos \varphi-a \cos \left[\varphi\left(1+\frac{r_{3}}{r_{4}}\right)\right] .
\end{aligned}
$$

As shown in Fig. 1, the form of the tooth profile of the cycloid disk is determined by the equations (4.5) and (4.6). Note that this profile is not the cycloid curve and also is not the epitrochoid curve, which is given by (4.11). In the case of $r_{c}=0$ from the equations (4.5) and (4.6) we return to the equations (4.11). In this case, if $a=r_{4}$ the equations (4.11) will give us an epicycloid curve, if $a>r_{4}$ - an inflected epicycloid curve and if $a<r-a$ quicked epicycloid curve.

Generally speaking, the last two curves also are called the epitrochoid curve. The name of the "cycloid disk" is more symbolical than real. We can use the equations (4.5) and (4.6) for programming in order to manufacture the cycloid disk in the CNC machines. This proves the need of the mathematical description of the teeth profiles of the cycloid disk.

To obtain the teeth profiles of the cycloid disk by trandistional method we may use a scheme of the engagement, as shown in Fig. 2. Here, the circle $r_{3}$ is related with an intermediate product of the cycloid disk, the circle $r_{4}$ is related with a main spindle of a gear-shaping machine and the circle $r_{c}$ is related with a pinion cutter. When we use a milling, boring or finishing machines the circle $r_{c}$ will be related with a milling, boring or finishing tools. Of course, it is necessary to add an accurate rotation transmission mechanism between the cicrle $r_{3}$ and the circle $r_{4}$. For the gear-shaping machine this transmission mechanism is attending.

\section{Recommended relationships}

Based on the theory and the terminology, which presented above, there are some frequently used geometric and kinematic relationships.

We begin with a short list and some comments on the terminology (see Fig. 1)

* The radius $r_{d}$ of the ring gear housing with rollers is given by:

$$
r_{d}=\overline{O_{2} M}=\overline{O_{1} O_{4}} .
$$

* The distance $A$ between gear centers is given by:

$$
A=\overline{O_{1} O_{2}}=r_{2}-r_{1},
$$


where, $r_{1}$ - the radius of the pitch circle of the cycloid disk

$r_{2}$ - the radius of the pitch circle of the ring gear housing with rollers.

Note that the two circles $r_{1}$ and $r_{2}$ were rolling upon each other without slipping. If the circle $r_{2}$ is rolling with an arc $2 \pi r_{2}$, the cicrle $r_{1}$ will be rolling with the arc $\left(2 \pi r_{1}+t\right)$, where $t$ is circular pitch. Therefore

$$
t=2 \pi\left(r_{2}-r_{1}\right)=2 \pi A \text {. }
$$

On the other side

$$
t=2 \pi r_{1} / Z_{1}
$$

where $Z_{1}$ - the teeth numbers of the cycloid disk

Consequently

$$
\begin{aligned}
& r_{1}=A Z_{1}, \\
& r_{2}=r_{1}+A=A\left(Z_{1}+1\right) .
\end{aligned}
$$

* As mentioned above, in the process of the tooth shaping we use the pitch circles with the radii $r_{3}$ and $r_{4}$. In the meantime, these pitch circles are rolling upon each other without slipping. Based on the ralationships in the Fig. 2, we have

$$
\begin{aligned}
& \frac{r_{3}}{r_{4}}=\frac{\overline{O_{4} M}}{r_{1}}=\frac{\overline{O_{1} O_{2}}}{r_{1}}=\frac{1}{Z_{1}}, \\
& r_{4}+r_{3}=\overline{O_{1} O_{4}}=\overline{O_{2} M}=r_{d}, \\
& r_{3}=r_{d} \frac{Z_{1}}{Z_{1}+1}, \\
& r_{4}=\frac{r_{d}}{Z_{1}+1} .
\end{aligned}
$$

* The dedendum circle $r_{i}$ and addendum circle $r_{e}$ are given by

$$
\begin{aligned}
& r_{i}=r_{d}-A-r_{c}, \\
& r_{e}=r_{d}+A-r_{c} .
\end{aligned}
$$

\section{Conclusions}

1) A "rolling gear" is new terminology. It is used in the planetary cycloid roller gear reducer. This is a new development of the mechanical products with the tendency to replace sliding friction by rolling friction.

2) The profound analysis of the properties of the new reducer identified its advantages and showed the prospect of its effectiveness. 
3) The obtained equations of the teeth profiles of the "cycloid" disk not only give us a convenient means of the comprehensive studies of the new reducer, but also allow us to manufacture it in the continuous path tape controlled machines.

4) The initiated method of the tooth shaping in the machines of the common use with the widely used tools, will promote the manufacturing of the new reducer.

5) The recommended relationships are a helpful documentation to design process of the new reducer.

\section{REFERENCES}

1. Koltrin N. I. Mechanics of machinery, "Mashinostroenhie", Leningrad, 1972 (in Russian).

2. Litvin F. L. Theory of gear engagement, "Nauka", Moscow, 1968 (in Russian).

3. Nguyen T. P. Foundations of theory of the elliptic contact of the space gear engagement, "Leningrad University of Technology", 1978 (in Russian)

Received May 31, 2002

\section{HộP GIẢM TỐC BÁNH RĂNG HÀNH TINH CON LĂN - CYCLOID}

Trong bài này trình bày các kết quá nghiên cứu về sự tạo hình biên dạng răng và phương pháp chế tạo chúng, về sự thiết lập các quan hệ của các thông số ăn khớp và về sự phân tích các đặc tính của loại hộp giảm tốc bánh răng hành tinh con lăn-cycloid.

Reseach Center of Automation

Hanoi University of Technology

1, Dai Co Viet Str, Hanoi, Vietnam

Tel. 84.4.8692207, Fax 84.4.8681099. 